Bull. Fac. Agric, Cairo Univ., 69:147-154 (2018).

\title{
THE PARTICIPATION OF SMALL-SCALE RURAL WOMEN PRODUCERS IN THE SUSTAINABLE LIVELIHOODS OF THEIR FAMILIES AND RELATIONSHIP TO CHANGES IN MILK PRODUCTION
}

(Received: 29. 4. 2018)

\author{
By \\ Manar A. Abdel-Hameed, Azza T. El-Bendary and E. A. M. Heikal \\ Department of Rural Sociology and Agricultural Extension, Faculty of agriculture, \\ Cairo University, Giza, Egypt
}

\begin{abstract}
The present study focuses on the changes that occurred in milk production, and the degree of suffering due to the resulting problems and the significance of the relationship between the studied samples and their suffering, and the relationship between the independent variables studied in the interpretation of difference between the researchers in terms of income from milk. The study was conducted in"Um-Khenan" village at Giza Governorate. The data were collected from 185 rural women involved in dairy farming practices through direct interviews using a questionnaire. The results showed the following.

One of the most important changes in milk production is the high prices of animals, medicines, feed and land rents, and increasing the suffering of the women from changes in milk production variably and, significant relationships were found between the variables of the number of female children, ownership of projects, resources of information, and the degree of suffering from the problems. There were five variables contributing $28.6 \%$ to the interpretation of the variation in income from milk sales and it's the total cost of feed per month, possession of household appliances, input problems, number of years of husband education, leadership. The main problems facing milk production are high feed prices, rising costs of medicines and treatments, and lower milk selling prices.
\end{abstract}

Key Words: milk production, rural women, suffering of changes.

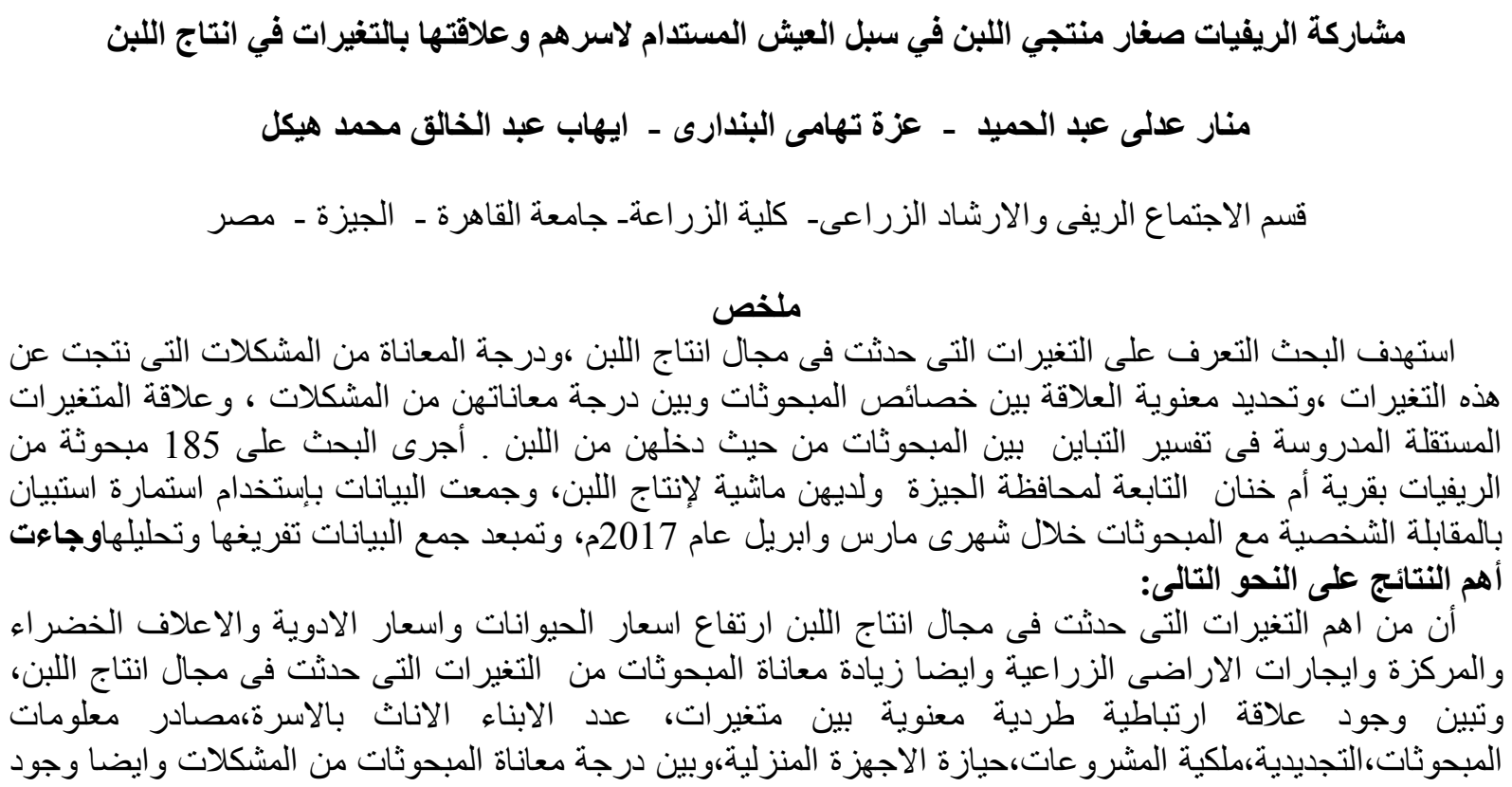




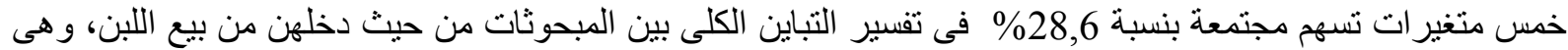

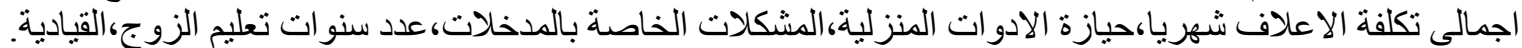

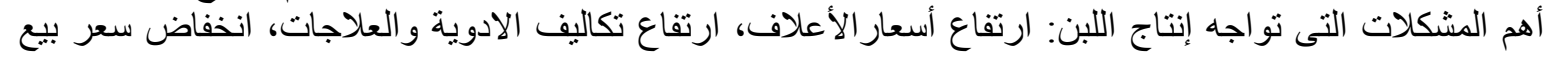

جنية من أجمالى الاخل القومى،وتساهم منتجات الالبان

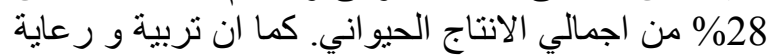

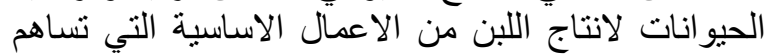

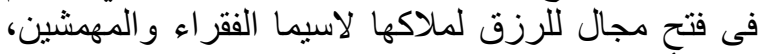

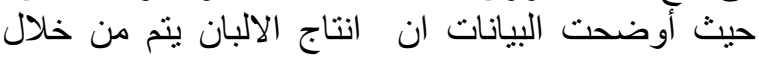

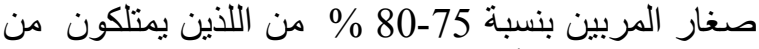

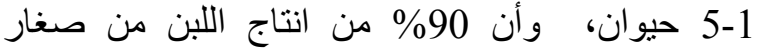

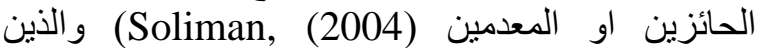
يعتمدون بشكل كبير علي الدخل من بين التئ اللبن ومنتجاتة

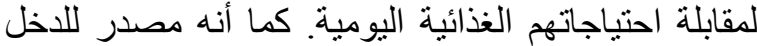

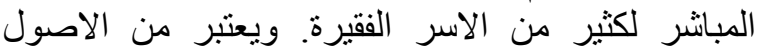

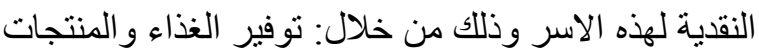

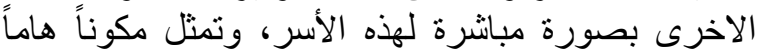

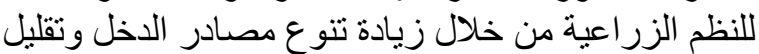

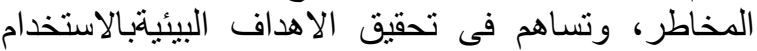

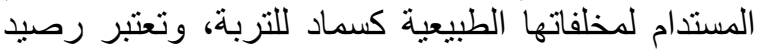
متاح للتصرف فيها بالبيع عند الحاجة الى رأس مال بشكلئ رنئ

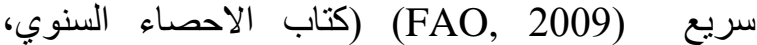
أوضحت بيانات المجلس القومى للمرأة (2016) ان

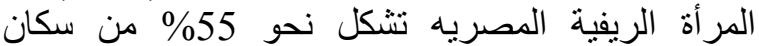
الريف، ويعمل نحو 42.8\% في الرئه المجال الزراعى بشقيه

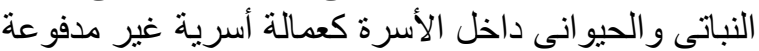

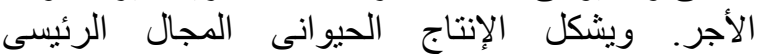

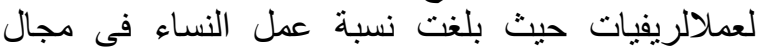

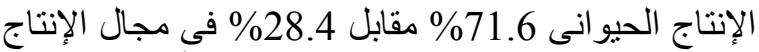

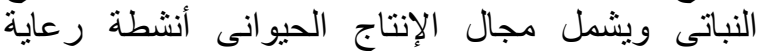

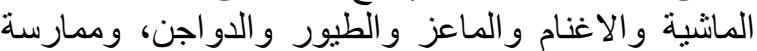

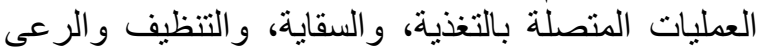

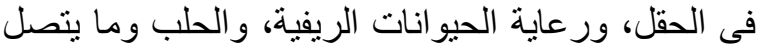

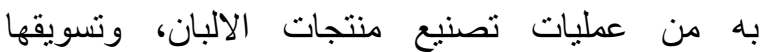
(العيسوى: 2003).

يعتبر اللبن منتج أساسى فى تغذية الانسان، وتمثل

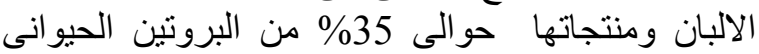

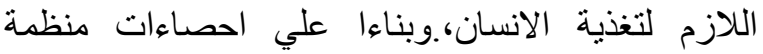

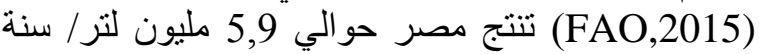

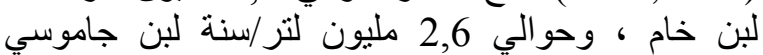

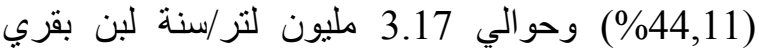
\%35,75). وبلغ متوسط نصيب الفرد من الالبان لتربن

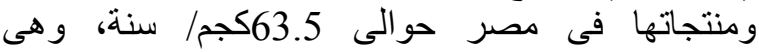
منخفضة عن الكمية التى توصى بهى بها منظمة الصحة الصحة

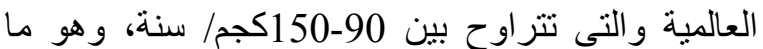
يدعوا الى الاهتمام بإنتاجها وتوفير بلى كل متطلباتها وحل المشكلات التى تواجهها (الشهاوي: 2012). وفي الاونه الاخيرة حدثت تغير ات حادي الات في الاقتصاد

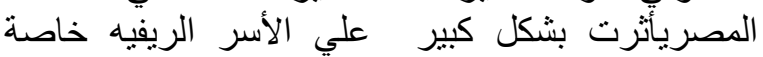

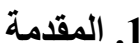

اكدت استراتيجية الأمم المتحده للتنمية المستدامة

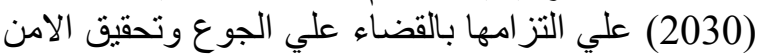

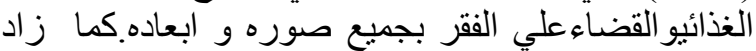

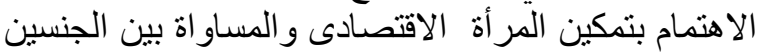

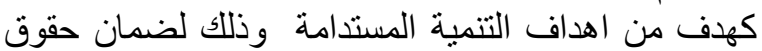
المرأة بشكل أساسي في كل هدف من أهداف التنمية التية

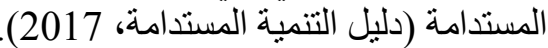
وتبذل الدوله كثير من الجهود لتنمية الريف التيف المصربلتحقيق أهداف التنميه وخفض متئ معدلات الفقر فيه.

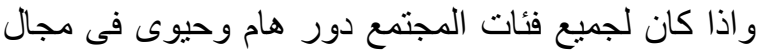

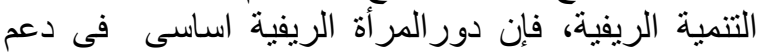

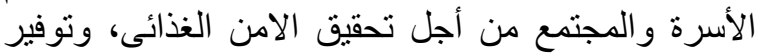

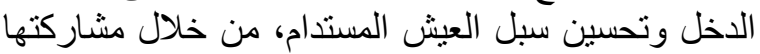

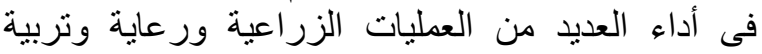

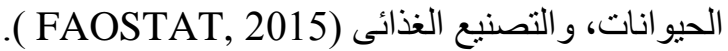
اوضحت ادبيات التنمية ان هناك علاقة بئن بين ديناميكيات مستوي المعيثة وأهمية وقيم الأصول المختية المتلفه بالنسبة

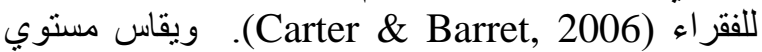

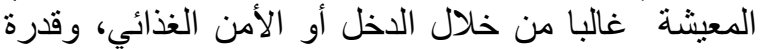

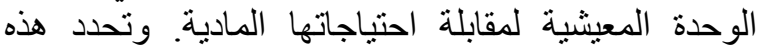

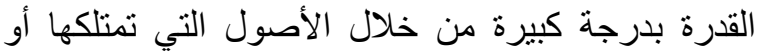

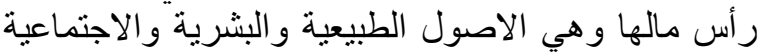

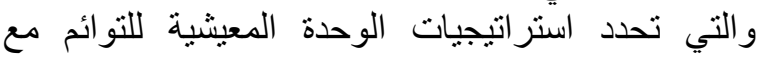
الاخطار و الصدمات (Spare and Moser, 2007).

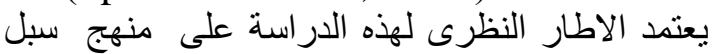

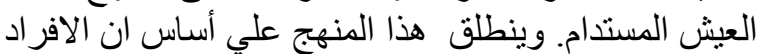

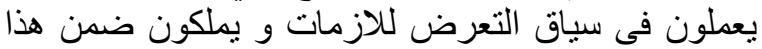

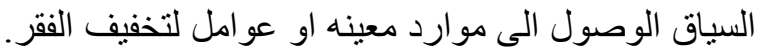

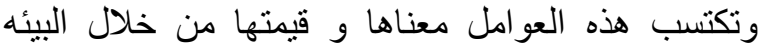

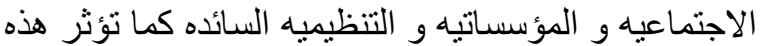

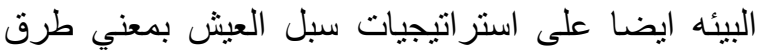

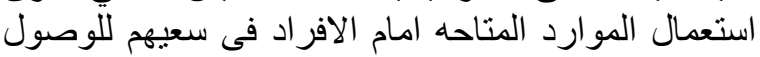

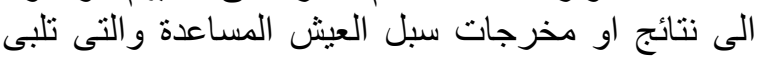

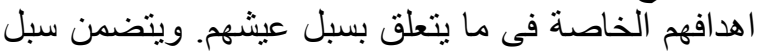

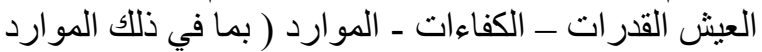

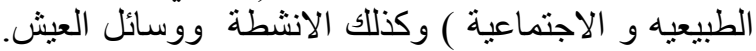

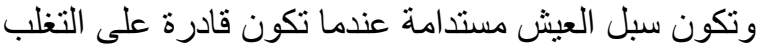

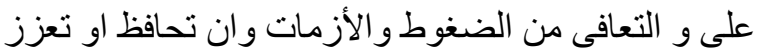

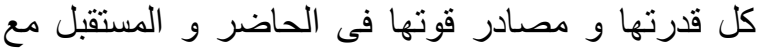

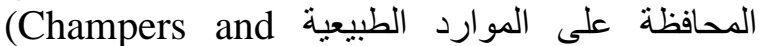

Conway, 1992).

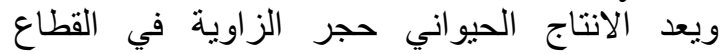

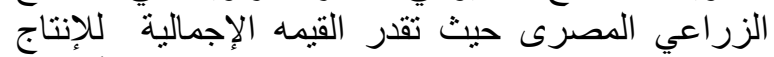

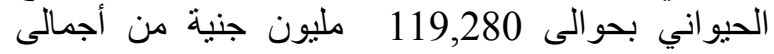
الدخل ألقوميو يقدر إنتاج الالبان بحوالى 24,890 مليون 


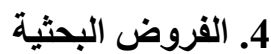

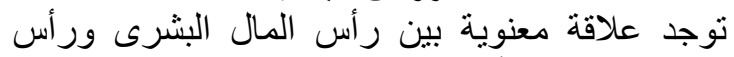

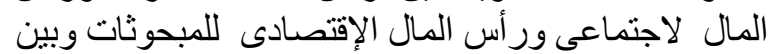
درجة معاناتهن من مشكلات إنتاج اللبن.

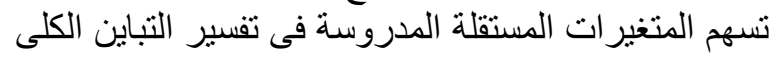

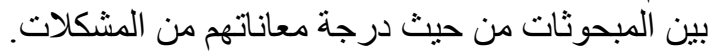

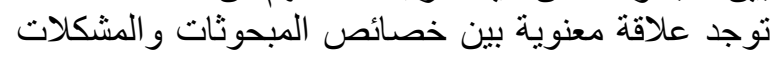

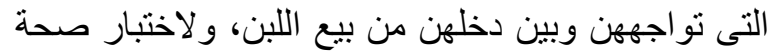

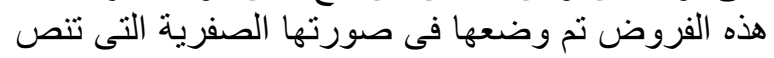
على عدم وجود علاقة معنوية.

\section{5. - 5 الطريقة البحثية}

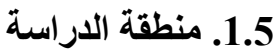

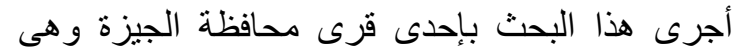

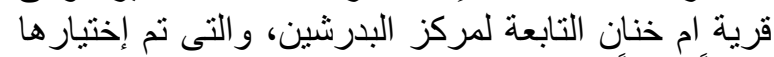

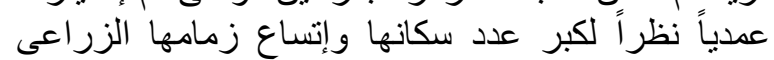

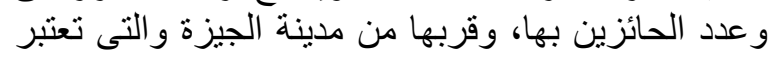

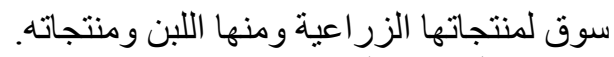

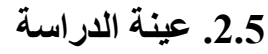
قد نم إختيار عينة بلغ عددها 185 مبحوثاً من زوجات التبات

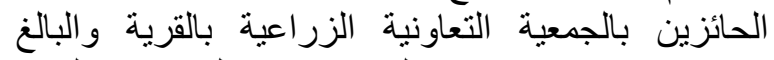
عددهم 1350ونبين ان حوالى الى 850 من الحائزين يملكون الأنئ حيوان على الأقل لانتاج اللبن. 3.5. جمع البيانات وأدوات التحليل الإني لاحصائى

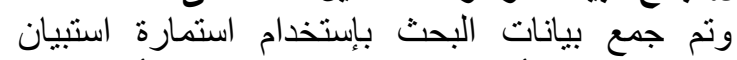

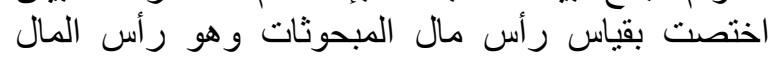

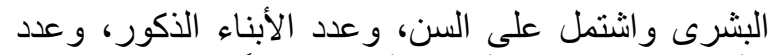

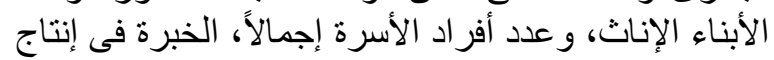

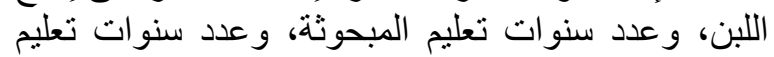

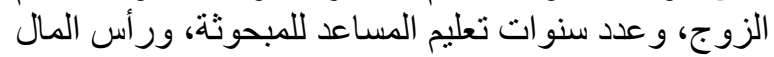

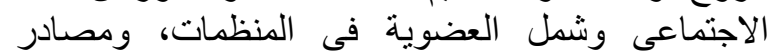

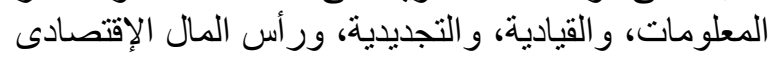

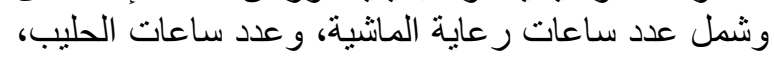
والحيازة الحيوانية، وحيازة الألات الزراعية وعية، والأجهزة المنزلية، و الدخل الشهرى النه للأسرة. 4.5. المفاهيم الإجرائية للمتغيرات ولاتيرة وطرق قياسها

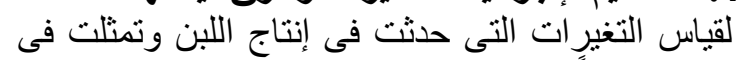

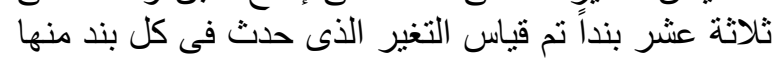

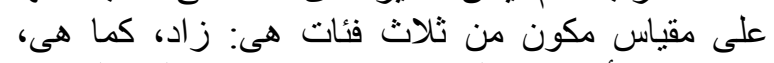

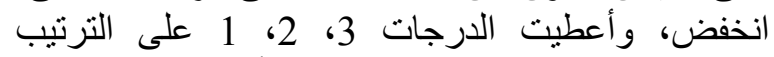

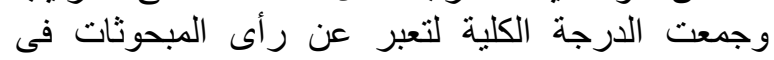

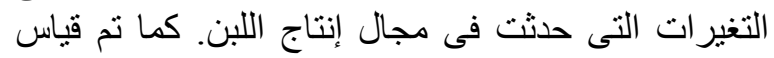

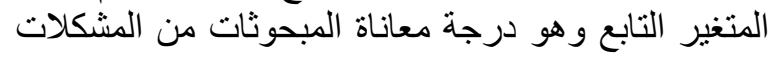

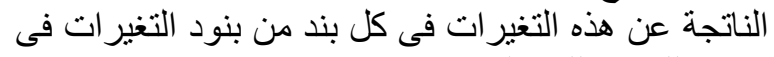

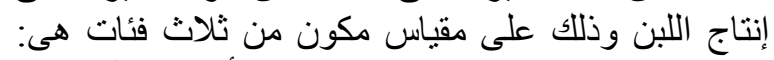

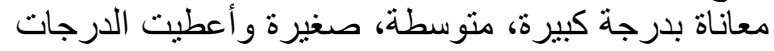

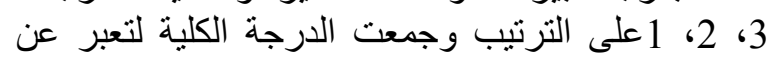

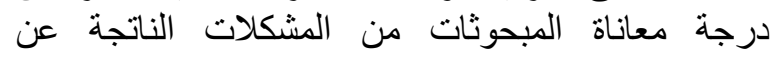

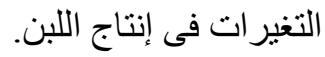

الفقيرة منها وزيادة معاناتها منالمشكلات التى تواجها تربية التهاية

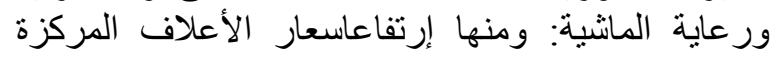

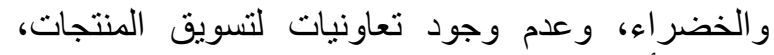

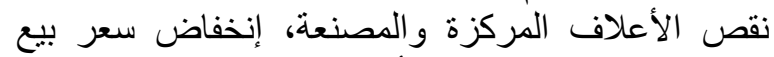
الحليب الذي تنتجه المرأة، إرتفاع تكاليف الإنة الادوية

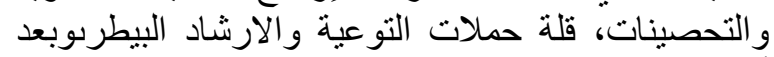
أسواق البيع وزيادة تكاليف التسويق.التهي الهيتي 2012).

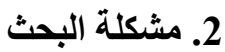

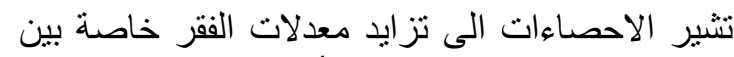

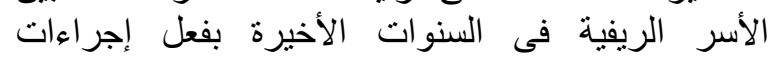

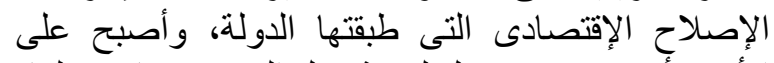

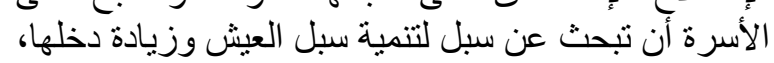

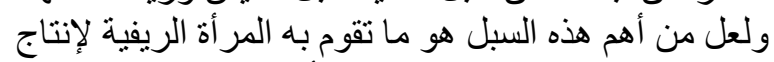

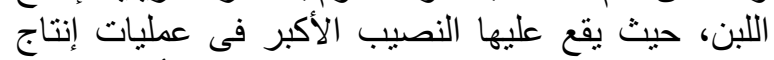

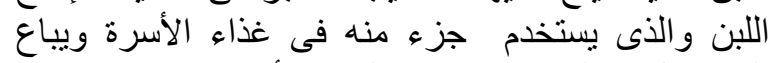

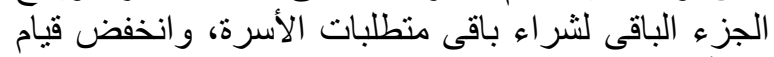

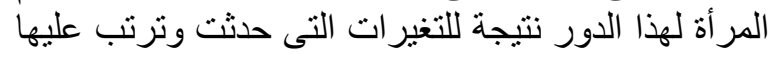

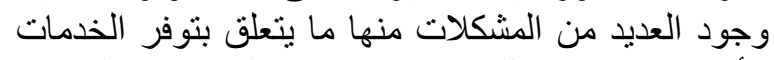

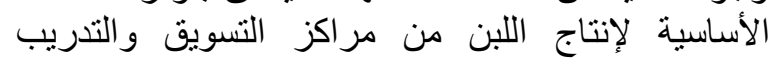

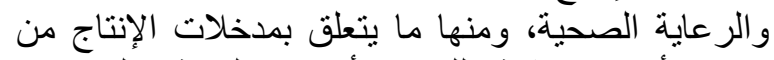

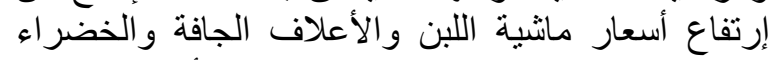

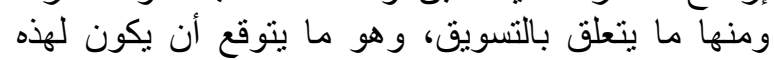

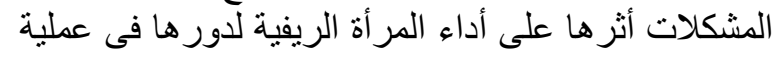

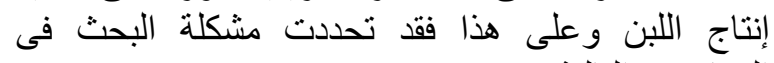
التساؤلات التنالية : التئ ما هى التغير ات التى حدثت فى مجال إنتاج اللبن لدى الأسر الريفية؟ مأ هى المشكلات التى تترتب على هذه التغير ات؟ ودرجة معاناة المبحوثات منهات

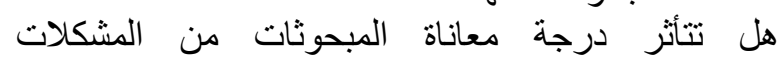
بخصائصهن المدروسة دربّ هل تؤثز خصائص المبرون المبحثات و المشكلات التى تواجهن

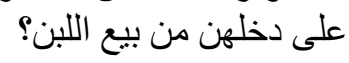

\section{3. أهداف البحث}

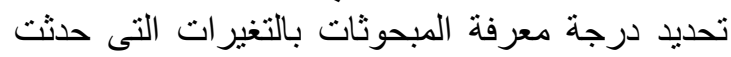

فى مجال إنتاج اللبن لدى الأسر الريفية

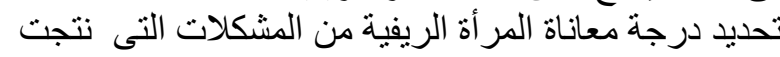

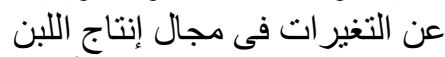

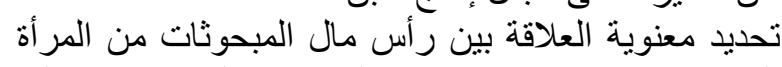

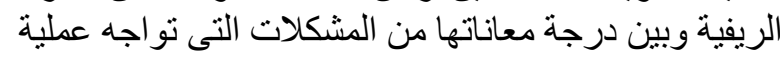
إنتاج وتسويق اللبن.

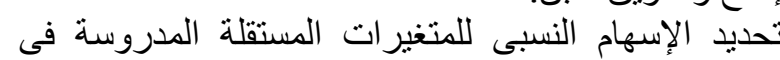

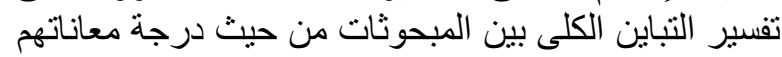
من المشكلات.

تحديد معنوية العلاقة بين خصائص المبحوثات و والمشكلات التى تو اجهن وبين دخلهن من بيع اللبن. 
2.6. درجة معاناة المبحوثات من المشكلات الناتجه عن التغير ات درهات

أوضحت النتائج جدول (2) الى زيات التئن معاناة المبحوثات

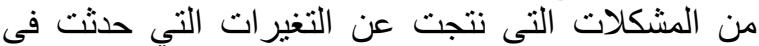

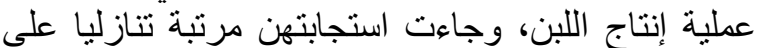
النحو التالى:جاء فى مقدمة المثكلات التى زئى زادت التهن معاناة

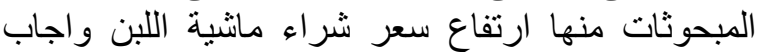
بذلك 97.3\% من المبحوثات، ثم ارتفاع القيمة الايجارية

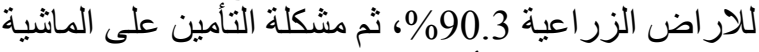

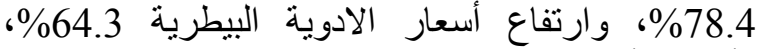

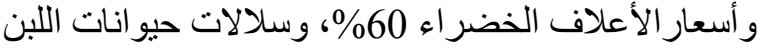

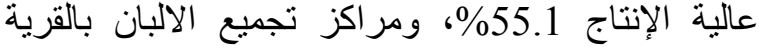

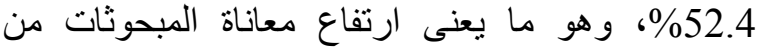

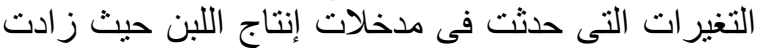

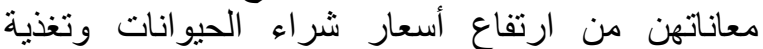

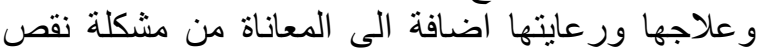

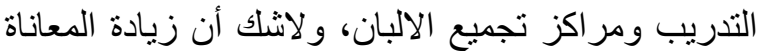

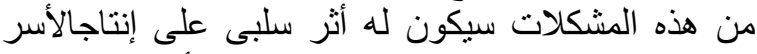
الريفية للالبان وبالتالى يؤثر على دخل الأسرة ومستوى لئى معيشتها.

3.6.علاقة رأس مال المبحوثات بلرجة معاناتهن من معن المشكلات

1.3.6.علاقة رأس المال البشرى للمبحوثات بدرجة

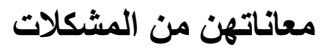

ينص الفرض الاحصائى الأول على أنه "لأن توجد الته
وقد تم جمع البيانات الميدانية خلال شهري مارس و

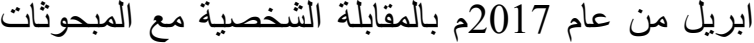
بقرية الدراسة وبعد جمع البيانات تم تفريغها وتحليلها باليها احصائياً بإستخدام جداول الحصر العدية العددى و النسب المئوية ومعامل الارتباط البسيط ليبرسون. واستخدم الاندئ التحدار

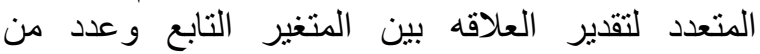
المتغير ات المستقله.

\section{6. كمائج البحث}

1.6 التغير ات فى عملية إنتاج اللبن التبن

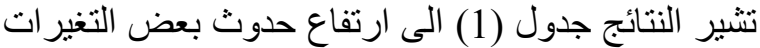

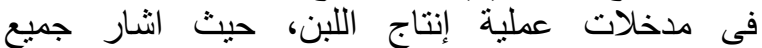

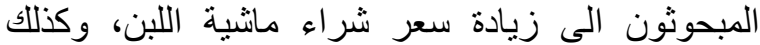

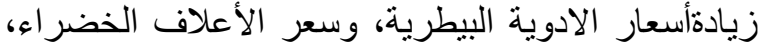

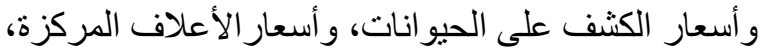

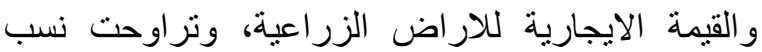

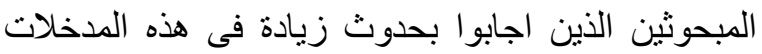

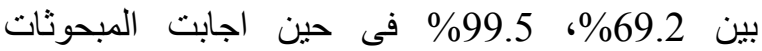
بإنخفاض كل التدريب على استخدام بدائل الأعلاف، وسلاتلات حيوانات اللبن عالية الإنتاج، ووجود بلتئ مراكز

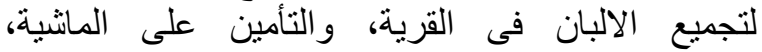
وتراوحت نسب استجابة المبحوثات على هذه البنود بين \%84.3، \% \% 0.3

واجاب بعض المبحوثات بعدم حدوث تغير في البنود

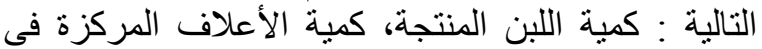

جدول (1) : توزيع المبحوثات وفقاً لاستجابتهن على مقار التغير الحادث فى مدخلات إنتاج اللبن فى السنوات الخمس الاخيرة.

\begin{tabular}{|c|c|c|c|c|c|c|c|c|c|}
\hline \multicolumn{2}{|c|}{ الاجمالى } & \multicolumn{2}{|c|}{ قلت } & \multicolumn{2}{|c|}{ كما هي } & \multicolumn{2}{|c|}{ زادت } & \multirow{2}{*}{ المدخلات مدى التغير } & \multirow[t]{2}{*}{ b } \\
\hline$\%$ & عدد & $\%$ & عدد & $\%$ & عدد & $\%$ & عدد & & \\
\hline 100 & 185 & - & - & - & - & 100 & 185 & سعر شراء الحيوان & 1 \\
\hline 100 & 185 & - & - & 1.1 & 2 & 98.9 & 183 & أسعار الادوية البيطرية & 2 \\
\hline 100 & 185 & - & - & 0.5 & 1 & 99.5 & 184 & سعر الأعلاف الخضراء & 3 \\
\hline 100 & 185 & 0.5 & 1 & 3.2 & 6 & 96.2 & 178 & أسعار الكثف على الحيوانات & 4 \\
\hline 100 & 185 & 4.4 & 84 & 42.7 & 79 & 11.9 & 22 & كمية اللبن المنتجة & 5 \\
\hline 100 & 185 & 13.5 & 25 & 8.1 & 15 & 78.4 & 145 & سعر بيع الحيوان & 6 \\
\hline 100 & 185 & 20.0 & 37 & 33.5 & 62 & 46.5 & 86 & كمية الأعلاف المركزة فى السوق صيفاً & 7 \\
\hline 100 & 185 & 1.6 & 3 & 2.2 & 4 & 96.2 & 178 & أسعار الأعلاف المركزة & 8 \\
\hline 100 & 185 & 53.0 & 98 & 32.4 & 60 & 14.6 & 27 & التّريب على استخدام بدائل الأعلاف & 9 \\
\hline 100 & 185 & 1.6 & 3 & 2.2 & 4 & 96.2 & 178 & القيمة الايجارية للاراضى الزراعية & 10 \\
\hline 100 & 185 & 50.3 & 93 & 31.9 & 59 & 17.8 & 33 & سلالات حيوانات اللبن عالية الإتتاج & 11 \\
\hline 100 & 185 & 67.0 & 124 & 20.0 & 37 & 13.0 & 24 & وجود مراكز لتجمع الالبان فى القرية & 12 \\
\hline 100 & 185 & 84.3 & 156 & 15.7 & 29 & - & - & التأمين على الماشية & 13 \\
\hline
\end{tabular}

علاقة معنوية بين رأس المال البشرى للمبحوثات ممثناً

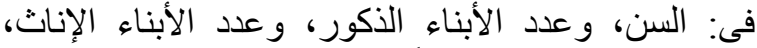

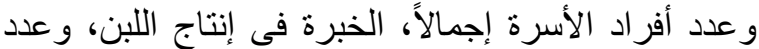

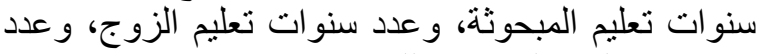

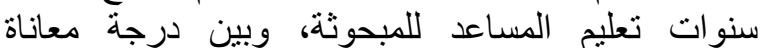

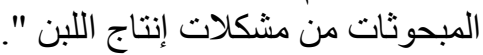

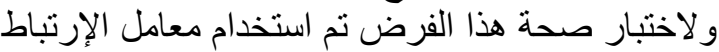

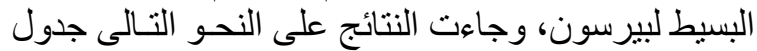

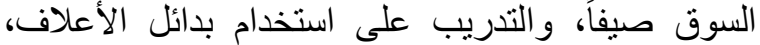

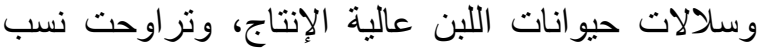

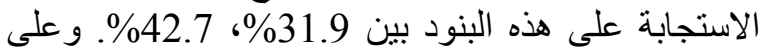
هذا يتضح حدوث تغير ات كبيرة النير في مدخلات إنتاج اللبن

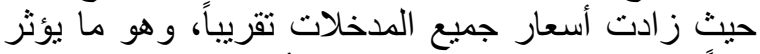

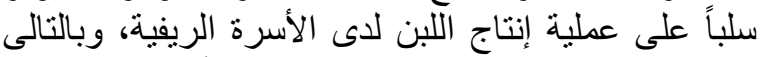

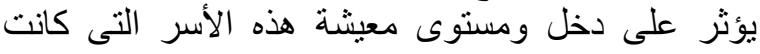
تعتمد على اللبن كمصدر مستدام لدخلها ومعيشتها. 
جدول (2) : توزيع المبحوثات وفقاً لرأيهن فى مدى معاناتهن من المشكلات الناتجة عن التغير الحادث فى إنتاج اللبن.

\begin{tabular}{|c|c|c|c|c|c|c|c|c|c|}
\hline \multicolumn{2}{|c|}{ 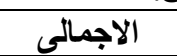 } & \multicolumn{2}{|c|}{ قتلت } & \multicolumn{2}{|c|}{ كما هي } & \multicolumn{2}{|c|}{ زادت } & \multirow{2}{*}{ المدخلات مدى التغير } & \multirow[t]{2}{*}{ م } \\
\hline$\%$ & عدد & $\%$ & عدد & $\%$ & عدد & $\%$ & عدد & & \\
\hline 100 & 185 & 0.5 & 1 & 2.2 & 4 & 97.3 & 180 & سعر شراء الحيوان & 1 \\
\hline 100 & 185 & 3.2 & 6 & 32.4 & 60 & 64.3 & 119 & أسعار الادوية البيطرية & 2 \\
\hline 100 & 185 & 1.1 & 2 & 38.7 & 72 & 60.0 & 111 & سعر الأعلاف الخضراء & 3 \\
\hline 100 & 185 & 6.5 & 12 & 49.7 & 92 & 43.8 & 81 & أسعار الكثف على الحيوانات & 4 \\
\hline 100 & 185 & 4.3 & 8 & 37.8 & 70 & 57.8 & 107 & كمية اللبن المنتجة & 5 \\
\hline 100 & 185 & 8.1 & 15 & 32.4 & 60 & $\mathbf{5 9 . 5}$ & 11 & سعر بيع الحيوان & $\overline{6}$ \\
\hline 100 & 185 & 8.1 & 15 & 43.8 & 81 & 48.1 & 8 & كمية الأعلاف المركزة في السوق صيفاً & 7 \\
\hline 100 & 185 & 3.8 & 7 & 12.4 & 23 & 38.8 & 155 & أسعار الأعلافالمركزة فى السوق شتاعاً & 8 \\
\hline 100 & 185 & 15.1 & 28 & 32.4 & 60 & 52.4 & 97 & التذريب على استخدام بدائل الأعلاف & ת \\
\hline 100 & 185 & 2.7 & 5 & 7.0 & 13 & 90.3 & 16 & القيمة الايجارية للار اضى الزراعية & $\mathbf{1 0}$ \\
\hline 100 & 185 & 8.1 & 15 & 36.8 & 68 & 55.1 & 102 & سلالات حيوانات اللبن عالية الإنتاج & 11 \\
\hline 100 & 185 & 16.7 & 31 & 30.8 & 57 & 52.4 & 97 & وجود مراكز لتجمع الالبان فى القرية & 12 \\
\hline 100 & 185 & 12.4 & 23 & 9.2 & 17 & 78.4 & 145 & التأمين على الماشيةً & 13 \\
\hline
\end{tabular}

(3). يبين وجود علاقة ارتباطية عكسية عند مستوى معنوية

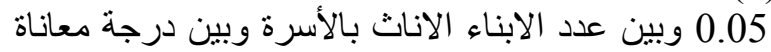

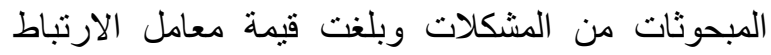
البسيط المحسوبة -0.153.

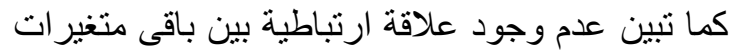

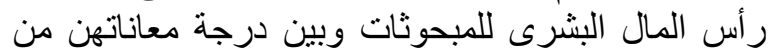
المشكلات.

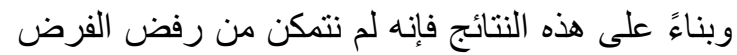

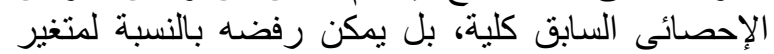

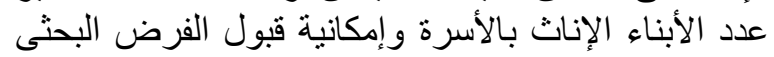
البديل بالنسبة لهذا المتغير.

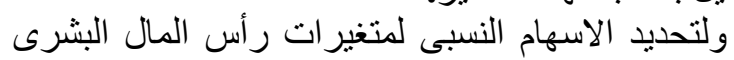

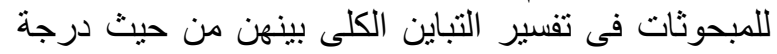

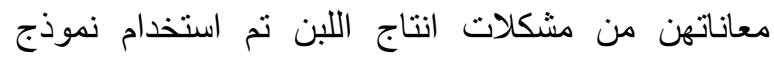
التحليل الارتباطى الانحدارى المتعدد، حيث تبين من نتائج

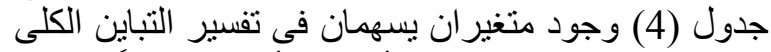

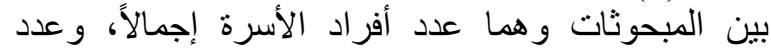
سنوات الخبرة فى انتاج اللبن، وبلغت التبن نسبة اسهامهما

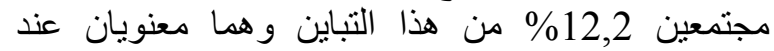
مستوى معنوية 0,01 حيث بلغت قيمة "Fن" لهذا الاسهام

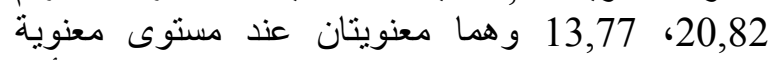
0,01.جدول (3):ييينقيمة معامل الارنباط البسيط بين رأس

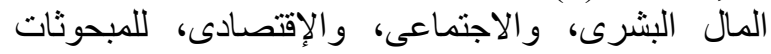
وبين دور هن في إنتاج اللبن.

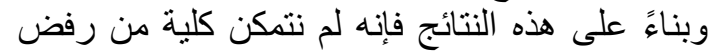

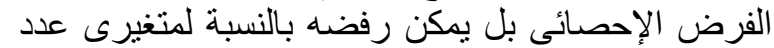
أفراد الأسرة إجمالاً، و عدد سنون ات الخبرة فى النتاج اللبن، لفيرى
جدول (3) : قيمة معامل الارتباط البسيط بين رأس الأسماع

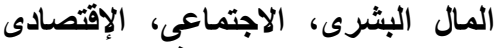

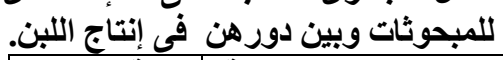

\begin{tabular}{|c|c|c|}
\hline قالارتباطة معامل & المتغيرات المستئلة التغابعة & s \\
\hline \multicolumn{3}{|c|}{ أولاً: رأس المال البشرى } \\
\hline 0.014- & السن & 1 \\
\hline 0.041 & عدد الابناء الذكور & 2 \\
\hline *0.153- & عدد الابناء الاناث & 3 \\
\hline 0.099- & عدد أفرَاد الأسرة إجمالاً & 4 \\
\hline 0.066 & الخبرة في إنتاج اللبن & 5 \\
\hline 0.086 & سنوات تعليم الأوجة & 6 \\
\hline 0.038- & سنوات تعليم الزوج & 7 \\
\hline 0.104- & سنوات تعليم المساعد & 8 \\
\hline \multicolumn{3}{|c|}{ ثانياً: رأس المال الاجتماعى } \\
\hline 0.096 & العضوية فى المنظمات & 1 \\
\hline$* 0.171$ & مصادر المعلومات & 2 \\
\hline 0.124 & القيادية & 3 \\
\hline$* 0.185$ & التجديدية & 4 \\
\hline \multicolumn{3}{|c|}{ ثالثاً: رأس المال الإقتصادى } \\
\hline$* * 0.256$ & ملكية المشروعات & 1 \\
\hline 0.074- & عداسـاعات رعاية الماثية & 2 \\
\hline 0.037 & عدد ساعات الحليب & 3 \\
\hline 0.055- & الحيازة الحيوانية & 4 \\
\hline 0.001- & حيازة الالات & 5 \\
\hline$* 0.178$ & الاجهزة المنزلية & 6 \\
\hline 0.061 & الدخل الثهرى للأسرة & \\
\hline
\end{tabular}

\begin{tabular}{|c|c|c|c|c|}
\hline قيمة معنوية & التراكمية للإسهام & معامل التحديد & معامل الإرتباط & المتغيرات \\
\hline$* * 20.82$ & 9.7 & 0.120 & 0.320 & عدد أفراد الأسرة إجمالاً \\
\hline$* * 13.77$ & 12.2 & 0.131 & 0.363 & عدد سنوات الخبرة فى انتاج اللبن \\
\hline
\end{tabular}


و الحيازة الحيوانية، وحيازة الألات الزراعية، والأجهزة

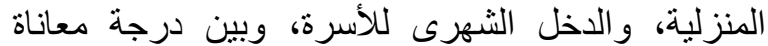

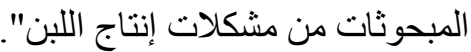

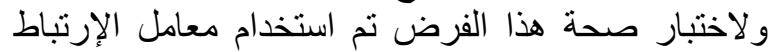
البسيط لبيرسون، وجاءت النتائج على النحو التالى في

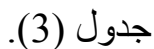
ـ تبين وجود علاقة ارتباطية طردية عند مستوى معنوية

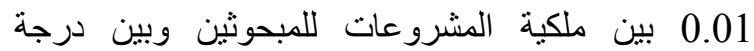

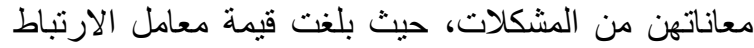
البسيط المحسوبة 0.256. ـ تبين وجود علاقة ارتباطية عكسية عند مستوى معنوية 0.05 بين ملكية الاجهزة المنزلية وبين درجة المبة المعاناة من فئن

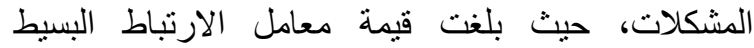

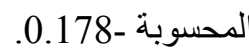
ـ عدم وجود علاقة ارتباطية بين باقى متغيرات رأس المال

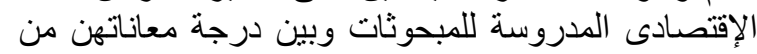
المشكلات.

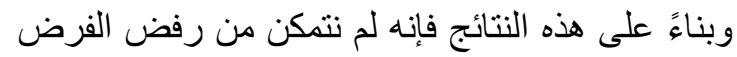

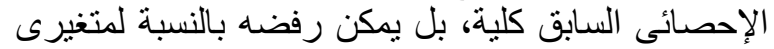

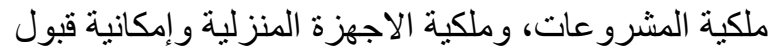
الفرض البحثى البديل بالنسبة لهذين المتغيرين.

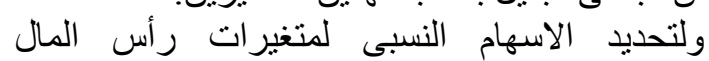

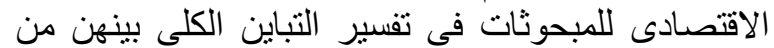

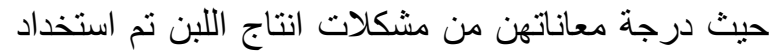

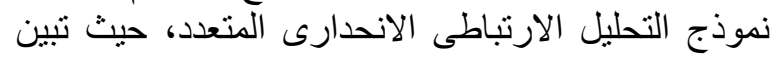

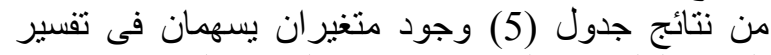
التباين الكلى بين المبحوثات وهما ولئ الحيازة الحيو انية، و وعدد

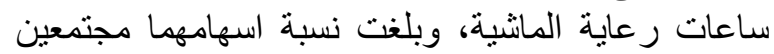
\% 8,8 من هذا التباين و هما معنويان عند مستوى معنوية الماثية

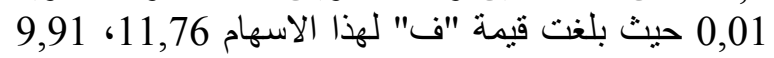
و هما معنويتان عندى مستوى معنوية 0,01.

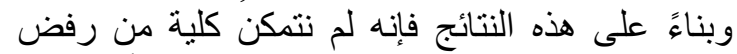

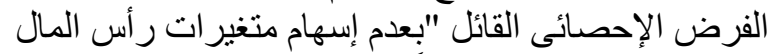

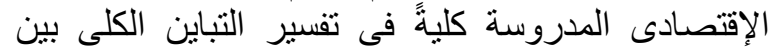

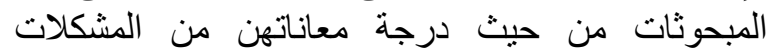
المدروسة" - مبته
و أمكانية قبول الفرض البحثى البديل لهذين المتغيرين،

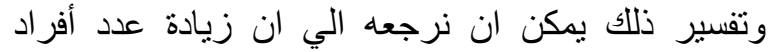

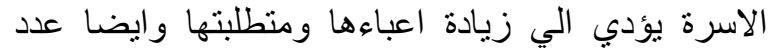

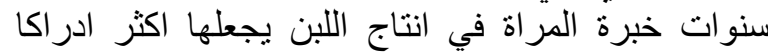

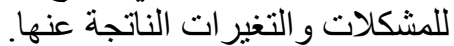

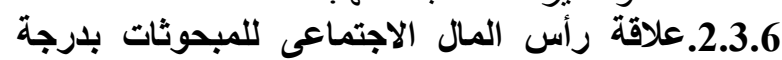

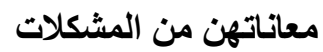

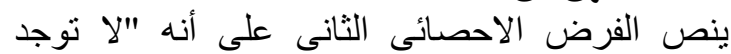

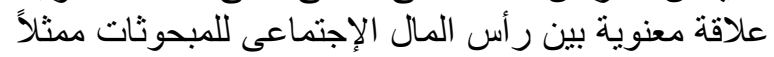

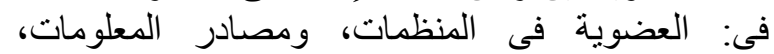
و القيادية، و التجديدية، وبين درجة معاناة المبحوثات من مشكلات إنتاج اللبن".

و لاختبار صحة هذا التساج الفرض تم استخدام معامل الإرتباط البسيط لبيرسون، وجاءت البتارته النتائج على النحو التالى في جدول (3).

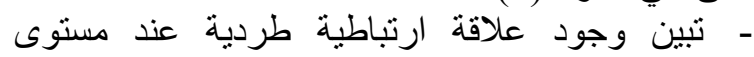

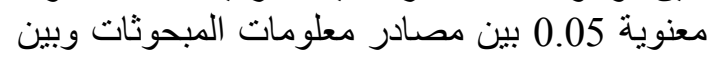

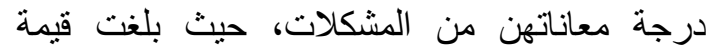
معامل الارتباط البسيط المحسوبة منية 0.171. تبين وجود علاقة ارتباطية عكسية عند مستوى معنوية 0.05 بين منغير التجديدية المبحوثات وبين

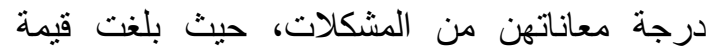
معامل الارتباط البسيط المحسوبة -0.185. -

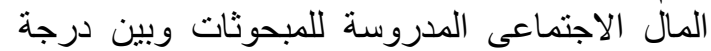

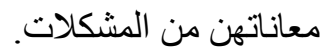

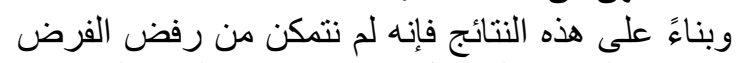

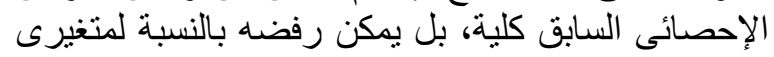

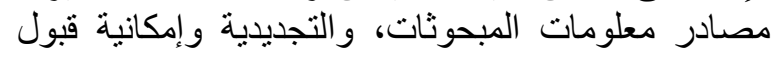
الفرض البحثى البديل بالنسبة لهذين المتغيرين.

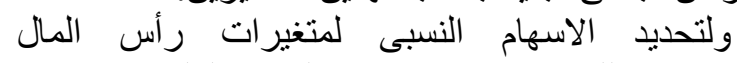

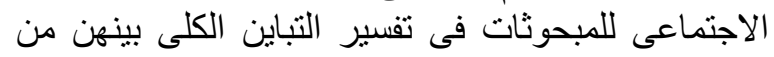
حيث درجة معاناتهن من مشكلات انتاج اللبن تم استخدام نموذج التحليل الارتباطى الانحدارى المتعدد، و الذى تئن تبين

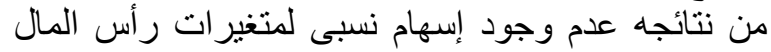
الإجتماعى للمبحوثات فى تفسير التباين الكلى بينهن من إنى

جدول (5): الاسهام النسبي لمتغيرات رأس المال الإقتصادى فى تفسير التباين الكلى بين المبحوثات من حيث درجة

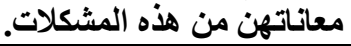

\begin{tabular}{|c|c|c|c|c|}
\hline قيمة معنوية & 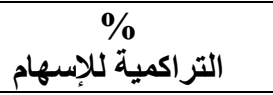 & معامل التحديد & معامل الإرتباط & المتغيرات \\
\hline$* * 11.76$ & 5.5 & 0.060 & 0.246 & الحيازة الحيوانية \\
\hline$* * 9.91$ & 8.8 & 0.098 & 0.313 & عدد ساعات رعاية الماثية \\
\hline
\end{tabular}

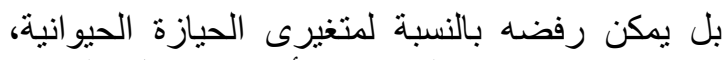

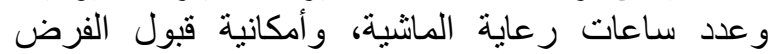

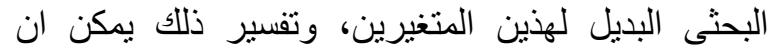

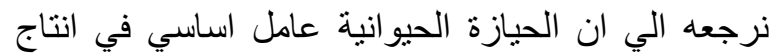

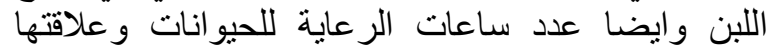
بدرجة المعاناة من المشكلة.
حيث درجة معاناتهن من مشكلات انتاج اللبن.

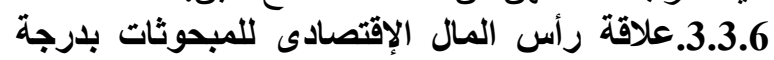

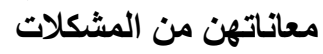

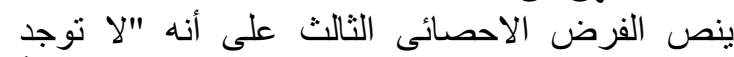
علاقة معنوية بين رأس المال الإقتصادى للمبحوثات ممثناً فى: عدد ساعات رعاية الماثية، وعدد ساعات الإنة الحليب، 
ـ ـوجود علاقـة ارتباطية عكسية عند مستوى معنوية 0,05 بين متغير المشكلات الخاصة بالة بالخدمات وبيندخلالمبحوثنات من بيع اللبن وبنات وبلغت قيمةمعامل الإرنباط البسيط المحسوبة -0,156. ـ عدم وجود علاقة ارتباطية بين باقى المتغيرات المبن المستقلة

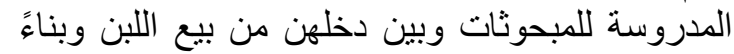

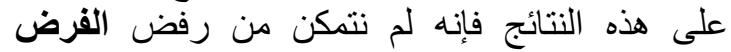

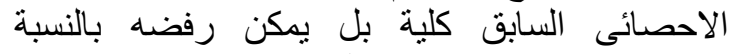

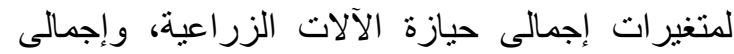

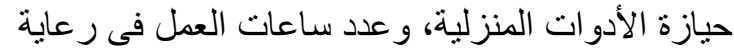

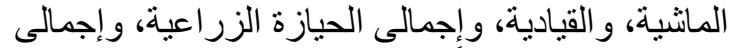

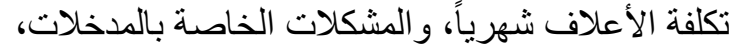

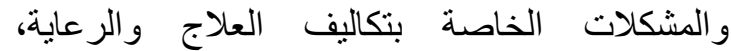

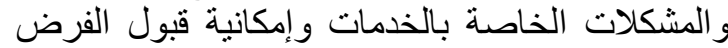
البحثى البديل بالنسبة لهذه المتغير ات اتلات
4.6.علاقة رأس مال المبحوثات و والمشكلات التى تواجهرن بلخلهن من بيع اللبن

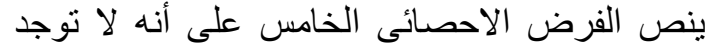

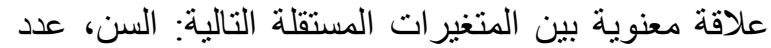

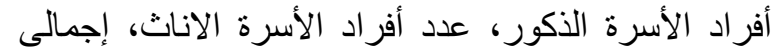

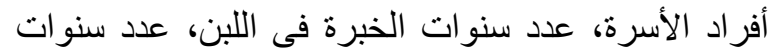

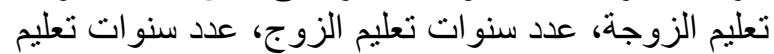

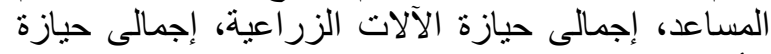

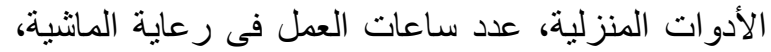

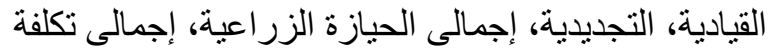

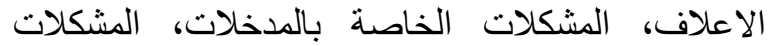

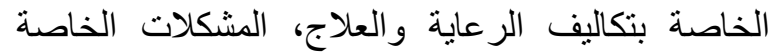

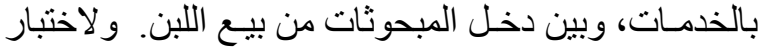

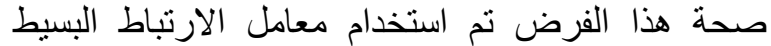
وجاءت النتائج (جدول 6) على النحو التالى:

جدول (6): قيم معامل الارتباط البسيط للعلاقة بين المتغيرات المستقلة للمبحوثات

بين إجمالى دخلهن من بيع اللبن.

\begin{tabular}{|c|c|c|}
\hline قيم معامل الارتباط البسيط & المتغيرات المستقلة & ? \\
\hline $\mathbf{0 , 0 8 0}$ & السن & 1 \\
\hline $\mathbf{0 , 0 8 3}$ & عدد أفراد الأسرة الذكور & 2 \\
\hline 0,027 & عدد أفراد الأسرة الاناث & $\mathbf{3}$ \\
\hline 0,01 & إجمالى أفراد الأسرة & 4 \\
\hline 0,093 & عدد سنوات الخبرة فى اللبن & 5 \\
\hline $0,037-$ & عدد سنوات تعليم الزوجة & 6 \\
\hline $0,040-$ & عداد سنوات تعليم الزوج & 7 \\
\hline $0,078-$ & عدد سنوات تعليم المساعد & 8 \\
\hline$* \mathbf{0}, \mathbf{2 7 9}$ & إجمالى حيازة الآلات الزراعية & 9 \\
\hline$* * 0,292$ & إجمالى حيازة الأدوات المنزلية & 10 \\
\hline$* * 0,330$ & عدد ساعات العمل فى رعاية الماثية & 11 \\
\hline$* * \mathbf{0 , 1 8 6}$ & القيادية & 12 \\
\hline $0,060-$ & التجديدية & 13 \\
\hline$* * 0,321$ & إجمالى الحيازة الزراعية & 14 \\
\hline$* * 0,471$ & إجمالى تكلفة الاعلاف & 15 \\
\hline$* 0,147$ & المشكلات الخاصة بالمدخلات & 16 \\
\hline$* 0,147$ & المشكلات الخاصة بتكاليف الرعاية والعلاج & 17 \\
\hline$* 0,156-$ & المشكلات الخاصة بالخدمات & 18 \\
\hline
\end{tabular}

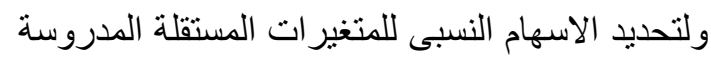

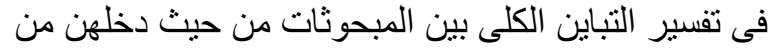
بيع اللبن تم استخدام نموذج التحليل الارنباطى الانيل التحدارى

المتعدد Step Wise.

$$
\text { تبين من النتائج (جدول 7) مانئ ما يلى: }
$$

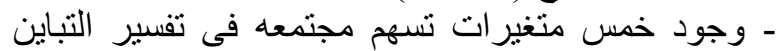

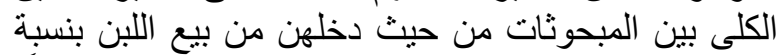

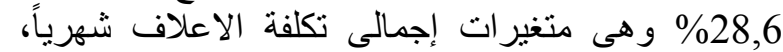

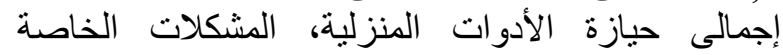

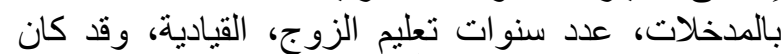

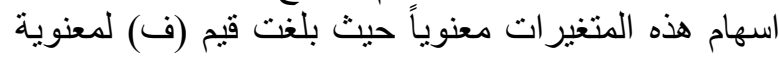

- وجود علاقة ارتباطية طردية عند مستوى معنوية 0,01 الإنية

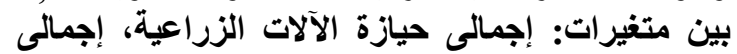

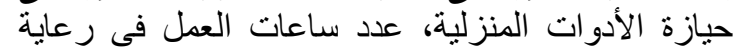

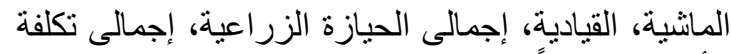

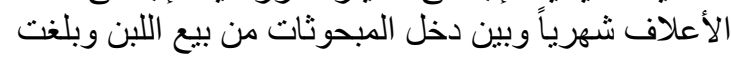

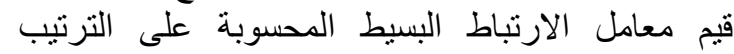

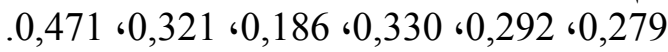
- وجود علاقة ارتباطية طردية عند مستوى معنوية 0,05

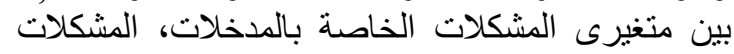

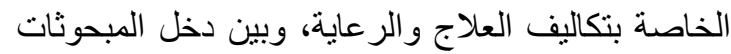

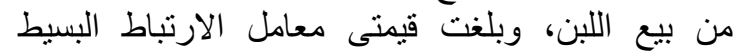
المحسوبتان0,147، 0,147 لكل منهما. 
جدول (7): الاسهام النسبى للمتغيرات المستقلة المدروسة فى تفسير التباين الكلى بين المبحوثات من حيث إجمالى دخولهن

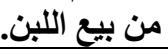

\begin{tabular}{|c|c|c|c|c|c|}
\hline قيمة ف لمعنويةً & التراكمية لاسهام & معامل التحديد & معامل الارتباط & المتغيرات & p \\
\hline$* * 52,15$ & 21,8 & 0,222 & 0,471 & إجمالى تكلفة الاعلاف شهرياً & 1 \\
\hline$* * 30,75$ & 24,4 & 0,253 & $\mathbf{0 , 5 0 3}$ & إجمالى حيازة الأدوات المنزلية & 2 \\
\hline$* * 22,61$ & 26,7 & 0,273 & 0,522 & المشكلات الخاصة بالمدخلات & 3 \\
\hline$* * 18,30$ & 27,3 & 0,289 & $\mathbf{0 , 5 3 8}$ & عدد سنوات تعليم الزوج & 4 \\
\hline$* * 15,74$ & 28,6 & 0,305 & $\mathbf{0 , 5 5 3}$ & القيادية & 5 \\
\hline
\end{tabular}

$$
\text { المجلس القومي للمر اة. ( 2016). مصر. }
$$

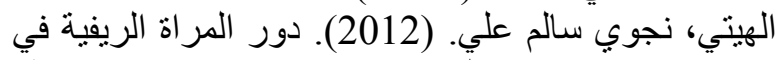

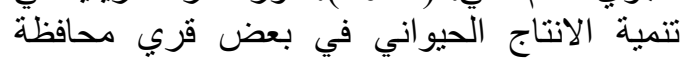

$$
\text { بغداد. }
$$

\section{REFERENCES}

Carter M.and Barret C. (2006). The economics of poverty traps and persistent poverty: as asset based approach, J. of Develop. Stud., 42(2):178-199.

ChambersR. and Conway G., (1992). Sustainable rural livelihoods: practical concepts for the $21^{\text {st }}$ Century. DiscussionPaper 296. IDS, Sussex

FAOSTAT (2015). Food and Agriculture Organization of the United Nations.

Food and Agriculture Organization (FAO)(2009). Sheep and Goats for Various Products and Benefits, FOA Variety Series, Handbook No.9 Rural Infrastructure and Industries Division, Rome, Italy.

Food and Agriculture Organization (FAO) (2010-2011)

http://faostat3.fao.org/browse/a/QA/E

http://www.fao.org/docrep/013/i2050e.pdf

Soliman I. (2004). The Role of Rural Women in Labor Use and Decision Making for Buffalo Enterprise in Egyptian Agriculture. Proceedings of the $7^{\text {th }}$ World BuffaloCongress, Organized by International Buffalo Federation contributed Papers, Volume, 2PP. 777783, Held in Manila, Philippine.

Spare and Moser (2007). International, Livestock Research Institute (ILRI),2010 Discussion Paper No.20.

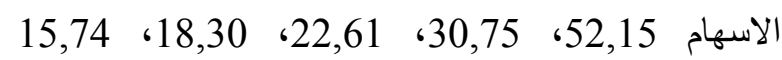

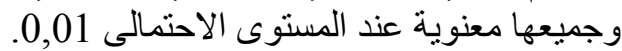
و هو ما يعنى أهمية هذه المتغير ات من أجل زئل زيادة دخل

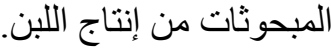

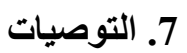

- فى ضوء الاتوصيات ما أوضحته النتائج من انخفاض كمية الاعلاف المركزة التى تغذى عليه التيها مانشية اللبن فإنه

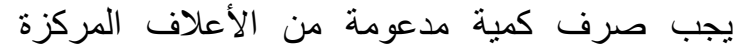

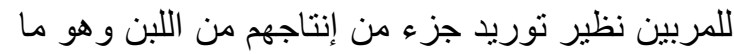
كانت تقوم به شركة سيكلام في السابق.

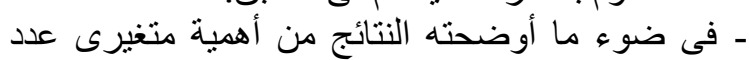

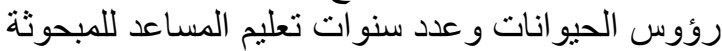

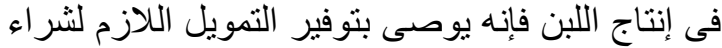

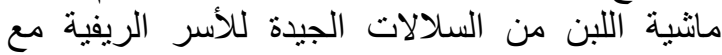
تيسير شروط الإقر اض و السداد الإن.

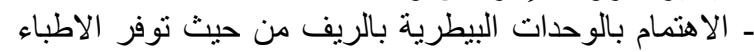
البيطيريين والادوية اللقاحات اللازمة من الإلية أجل تخفيف

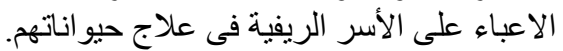

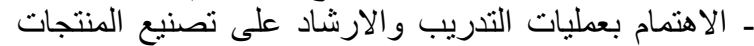

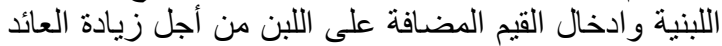
المتحقق للاسر من بيع هذه المنتجات.

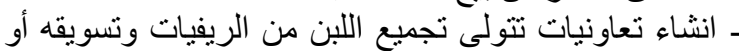

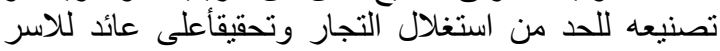
الريفية من إنتاج وبيع اللبن.

$$
8
$$

دليل التنمية المستدامة. (2017). معهد التخطيط القومي.مصر.

الثهاوي، محمد ابراهيم محمد. (2012). تحليل اقتصادي لانتاج وتسويق واستهلاك الالبان و الهم منتجاتها في

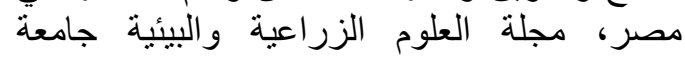

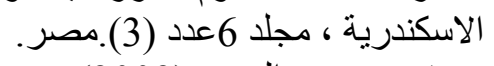

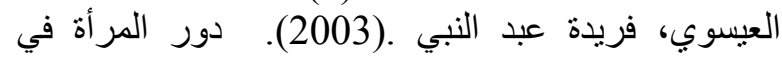

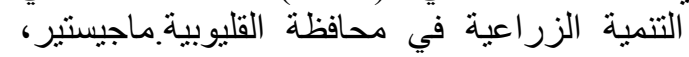

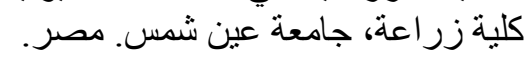
كتاب الاحصاء السنوي - الباب الخامســ الزراعة اعة، نشرة احصاءات الثروة الحيوانية، وزارة الزيات الزراعة واستصلاح الار اضي. 